\title{
Aquatic vegetation in deep lakes: Macrophyte co-occurrence patterns and environmental determinants
}

\author{
Mattia M. AZZELLA, ${ }^{1 *}$ Mariano BRESCIANI, ${ }^{2}$ Daniele NIZZOLI,${ }^{3}$ Rossano BOLPAGNI ${ }^{3}$ \\ ${ }^{1}$ Via G. Bellucci 94, 00156 Rome; ${ }^{2}$ Institute for Electromagnetic Sensing of the Environment, National Research Council (IREA-CNR), \\ Via Bassini 15, 20133 Milan; ${ }^{3}$ Department of Chemistry, Life Sciences and Environmental Sustainability, University of Parma, Viale \\ G.P. Usberti 33/A, 43124 Parma, Italy \\ *Corresponding author: mattia.azzella@gmail.com
}

\begin{abstract}
Our aims were to test the hypothesis that in deep lakes the co-occurrence patterns of macrophytes are not random, and to compare the relative contribution of the main environmental determinants (light, water and sediment parameters, phytoplankton) in structuring aquatic vegetation. We collected data from five deep Chara-dominated lakes in Central Italy along gradients of depth (33 to $165 \mathrm{~m}$ ), dimension (1.7 to $114.5 \mathrm{~km}^{2}$ ) and water trophic conditions (12.4 to $41.3 \mu \mathrm{g} \mathrm{L} \mathrm{L}^{-1}$ of total phosphorous). Twenty-five sampling plots per lake were randomly selected at five predetermined depths $(1.5,3.0,6.0,12.0$ and 20.0 m; $\mathrm{n}=5)$ within homogenous littoral sectors. Data were explored by a null model analysis using the checkerboard score (C-score) index, and Canonical Correspondence Analysis. Our data verify the not random co-occurrence patterns of macrophyte' communities in deep lakes. However, present data suggested that C-scores are strictly dependent on lake' trophic status: low nutrient loads, in both water and sediments, seemed to be reflected in a not random co-occurrence zonation of macrophytes. Summarizing, it is fundamental evaluate the local effects of lake trophy on the macrophyte community dynamics both in time and space before inquiring about mutual links. If it fails to assess macrophyte co-occurrence patterns, it may be not possible to identify the determinants of the spatial arrangement of macrophytes and, in turn, the conservation status or the ongoing dynamics of lakes.
\end{abstract}

Key word: Aquatic plants; C-score index; co-occurrence analysis; environmental drivers; Chara-dominated lakes; Volcanic lakes; central Italy.

\section{INTRODUCTION}

Ecological studies generally assume that the co-occurrence patterns of plants are non-random. However, the type of response of plant species and/or communities to environmental gradients is still strongly debated, with a range of evaluation models having been proposed (e.g., null models, nested or checkerboard patterns; Presley et al., 2010; Logue et al., 2011; Ulrich and Gotelli, 2013). In this context, the large amount of plant community studies have generally failed to investigate whether the structure of communities is non-random before analyzing their environmental determinants (Duberstein et al., 2014).

With regard to macrophyte communities, the majority of researchers have not taken into account the potential causality or randomness of their co-occurrence (Penning et al., 2008a), and very few works have evaluated the factors that may influence aquatic vegetation itself (Boschilia et al., 2008; Logue et al., 2011; Chmara et al., 2013). In any case, we exclude the possibility that macrophyte communities respond randomly to environmental gradients. This is in agreement with the observations about the non-random distribution of trait performance within macrophyte communities (Fu et al.,
2014). However, in specific situations (e.g., under anthropogenic stress), we hypothesize that macrophyte cooccurrence patterns may be unstable, which would result in unclear spatial gradients, affecting the identification of environmental determinants and limiting the use of macrophytes, for example, as bioindicators (Bolpagni et al., 2016a).

A non-random structure in macrophyte communities is based on the assumption that one or more factors contribute to its spatial pattern. As reported by Boschilia et al. (2008), these factors can be of either a competitive or environmental type, and lead to a checkerboard pattern produced by pairs of species with mutually exclusive ranges, as occurs among terrestrial plant communities (see Diamonds, 1975). Some previous works have generally concluded that the non-random distribution patterns of macrophyte communities tend to be driven by environmental factors rather than biotic interactions (Boschilia et al., 2008), a finding that is consistent with those of many other studies (Keddy, 1983; Wilson and Keddy, 1986). The main environmental factors that influence the structure of macrophyte communities are light availability, water and sediment parameters, and hydro-morphological determinants (Bornette and Puijalon, 2011 and references therein). Furthermore, their 
influence also varies markedly depending on the spatial scale at which they are analyzed as well as on the heterogeneity of the aquatic ecosystems being investigated (Lacoul and Freedman, 2006; Bornette and Puijalon, 2011). The listed variables can assume a greater or lesser importance according to the type of aquatic ecosystems (e.g., lakes, streams, lagoons, wetlands). In general, several studies have suggested that there is a direct dependence of macrophytes distribution on the simultaneous variation in light availability and temperature regime along the depth gradient (Azzella et al., 2014). The progressive worsening in the quality of lake water and of the sediment leads to a reduction in light availability, and a strong cascade effect on macrophytes presence and distribution (Genkai-Kato and Carpenter, 2005). On the other hand, when conditions in a lake improve, a new equilibrium in macrophyte communities' distribution is achieved. Focusing on deep lakes, we generally hypothesized that macrophyte communities may display local random distribution patterns under worsening (e.g., increased nutrient content or turbidity) or improving (e.g., increased transparency) water and sediment parameters, and that macrophytes distribution is not random exclusively in the presence of stable physical and chemical states, both in time and space. As a result, it is possible to identify the ecological determinants of macrophyte richness and community dynamics, as well as the significance of macrophyte indices (Melzer, 1999; Penning et al., 2008b; Kolada, 2010), only when physical and chemical conditions remain stable over time.

Within this context, a further critical aspect is the overestimation of the role of water quality compared to that of sediment or other not trophic factors (Carignan and Kalff, 1980). To fill this gap in our knowledge, in the present work we conducted a detailed investigation of both the sediment parameters and water in relation to the structure and composition of macrophyte communities. We hypothesized that the concentration of nutrients in surficial sediments (especially phosphorous) can shed light on dif- ferences that are to be expected between different lakes. Furthermore, our data could be used to discuss the significance of the presence or absence of a non-random co-occurrence pattern in macrophyte distribution for the purposes of an ecological assessment of a lake.

Bearing all this in mind, and considering that failure to assess community structure when macrophyte co-occurrence is analyzed significantly reduces the explicative power of the environmental determinants, this paper was to evaluate the macrophyte co-occurrence patterns by considering a homogeneous set of five natural deep lakes characterized by a gradient in trophic status. A second aim was to assess the role of non-random macrophyte co-occurrence patterns in affecting the analysis of edaphic factors (i.e., environmental determinants).

\section{METHODS}

\section{Study area}

The study was conducted in the Italian volcanic lake system on five deep lakes (lakes Bolsena, Bracciano, Martignano, Nemi, and Vico) with a mean depth and area of $91 \mathrm{~m}$ and $37.7 \mathrm{~km}^{2}$, respectively (Fig. 1; Tab. 1). The lakes investigated are oligo-mesotrophic, with total phosphorous (TP) and nitrogen (TN) mean concentrations of 24.9 and $600 \mu \mathrm{g} \mathrm{L}^{-1}$, respectively (Tab. 1). The lakes have a mean conductivity value of $429 \mu \mathrm{S} \mathrm{cm}^{-1}$, and mean Secchi disk transparency of $6.6 \mathrm{~m}$ (summer-winter mean value for the period 2006-2011). These characteristics support the classification of these lakes as belonging to the Charadominated lakes (Jensen, 1979), as is confirmed by the fact that their littoral vegetation is generally dominated by stoneworts (Chara globularis Thuillier 1799, C. polyacantha A. Braun in Braun, Rabenhorst \& Stizenberger 1859, C. tomentosa Linnaeus 1753) from a depth of three to 20 meters. Indeed, these lakes may be considered a European hotspot of stonewort biodiversity and hosted about the $20 \%$ of the European stoneworts diversity (Azzella,

Tab. 1. Morphometric characteristics and hydrochemical features (summer-winter mean values for the period 2010-2011) of the five lakes sampled.

\begin{tabular}{|c|c|c|c|c|c|c|c|c|c|c|}
\hline \multirow[t]{2}{*}{ Lake } & \multicolumn{5}{|c|}{ Morphometric characteristics } & \multicolumn{5}{|c|}{ Hydrochemical features } \\
\hline & $\begin{array}{c}\mathrm{D} \\
(\mathrm{m})\end{array}$ & $\begin{array}{c}A \\
\left(\mathrm{~km}^{2}\right)\end{array}$ & $\begin{array}{c}\text { Alt } \\
\text { (m asl) }\end{array}$ & $\begin{array}{l}\mathrm{Z}_{\max } \\
(\mathrm{m})\end{array}$ & $\begin{array}{c}\text { Vol } \\
\left(\mathrm{m}^{3} 10^{6}\right)\end{array}$ & $\begin{array}{c}\mathrm{TP} \\
\left(\mu \mathrm{g} \mathrm{L}^{-1}\right)\end{array}$ & $\begin{array}{c}\mathrm{TN} \\
\left(\mu \mathrm{g} \mathrm{L}^{-1}\right)\end{array}$ & $\begin{array}{c}\text { Cond } \\
\left(\mu \mathrm{S} \mathrm{cm} \mathrm{cm}^{-1}\right)\end{array}$ & $\mathrm{pH}$ & $\begin{array}{l}\text { SD } \\
\text { (m) }\end{array}$ \\
\hline Bolsena & 151 & 114.5 & 305 & 146 & 8922.0 & 15.8 & 710 & 523 & 7.4 & 7.5 \\
\hline Bracciano & 165 & 57.5 & 164 & 160 & 4950.0 & 12.4 & 510 & 519 & 7.9 & 8.7 \\
\hline Martignano & 60 & 2.5 & 207 & 54 & 71.2 & 37.7 & 410 & 392 & 7.4 & 6.5 \\
\hline Nemi & 33 & 1.7 & 318 & 34 & 32.5 & 41.3 & 900 & 340 & 7.9 & 5.0 \\
\hline Vico & 48 & 12.1 & 507 & 50 & 268.0 & 17.1 & 660 & 371 & 7.6 & 5.5 \\
\hline
\end{tabular}


2014). Only the first few meters (a depth of 1 to $4 \mathrm{~m}$ ) could be dominated by vascular species [e.g., Myriophyllum spicatum L., Phragmites australis (Cav.) Trin. ex Steud., Potamogeton pectinatus L., P. perfoliatus L.].

\section{Experimental design and macrophyte characterization}

A homogenous littoral sector, with a low to moderate slope of the bottom, was selected in each lake according to previous macrophyte surveys (Azzella et al., 2013).
Each sector was characterized by the absence of rocky outcrops or other morphological peculiarities that might affect the presence of macrophytes. A GIS program (ESRI's ArcGIS 10.0) was used in each sector to generate a grid with a 50-m mesh net on a one km-long stretch of coast (Fig. 2). Twenty-five squares of the grid were then selected at five different predetermined depths, with plots being drawn randomly from among plots that intercepted a bathymetric reference level. The predetermined depths were chosen based on a logarithmic increase between one

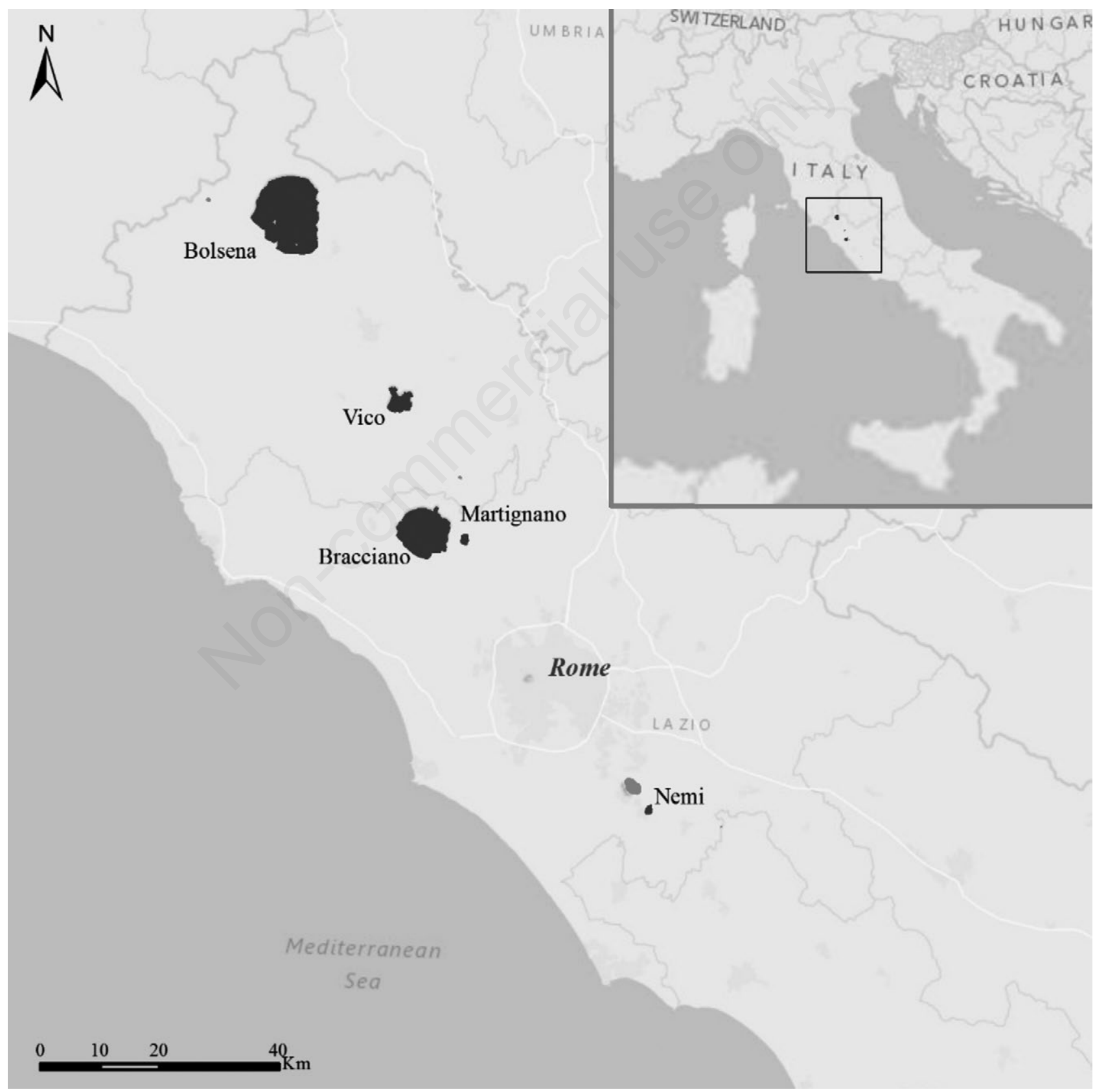

Fig. 1. Study area showing the location of the five lakes investigated. 
depth and the next $(1.5,3.0,6.0$, and $12.0 \mathrm{~m})$ with the exception of the greatest depth which was set at $20.0 \mathrm{~m}$. This method was adopted to prevent the sample plots from overlapping the thresholds between the different macrophyte communities previously recorded (Azzella et al., 2013; Azzella, 2014), and to ensure that they fell within each of the characteristic belts of macrophyte communities, according to the following general zonation:

i) $1.5 \mathrm{~m}$ depth corresponds to the high diversity emergent vegetation belt dominated by helophytes [e.g., $P$. australis, Schoenoplectus lacustris (L.) Palla] and vascular hydrophytes (e.g., M. spicatum, P. perfoliatus);

ii) $3.0 \mathrm{~m}$ depth corresponds to the high diversity Chara aspera-dominated belt;

iii) $6.0 \mathrm{~m}$ depth corresponds to the low diversity and high biomass C. polyacantha or C. tomentosa-dominated belts;

iv) $12.0 \mathrm{~m}$ depth corresponds to the very low diversity $C$. globularis-dominated belt;

v) $20.0 \mathrm{~m}$ depth corresponds to the rather monospecific Nitella opaca-dominated belt or to bare sediment.
We thus obtained five sample plots for each depth in each lake, which corresponds to 25 plots per lake and a total of 125 plots. All the plots were sampled in summer 2013. During the field activities, each sample plot was reached using a Trimble GPS GeoXM and the depth measured with a depth gauge $( \pm 0.5 \mathrm{~m})$. If the predetermined depth (sample plot) and the measured depth in situ corresponded, we proceeded with the sampling activities; if they did not correspond, we moved perpendicularly to the coastline until the desired depth was reached. A square whose sides measured $1 \mathrm{~m}$ was lowered on the sampling plot, and all the species present and the relative cover (expressed as \%) were recorded by visual assessment within the square using an underwater camera or by scuba diving.

\section{Water and sediment physical and chemical characterization}

At each sampling plot, temperature (T), conductivity (Cond), $\mathrm{pH}$ and dissolved oxygen (DO) were measured directly in situ just above the canopy of the macrophyte com-

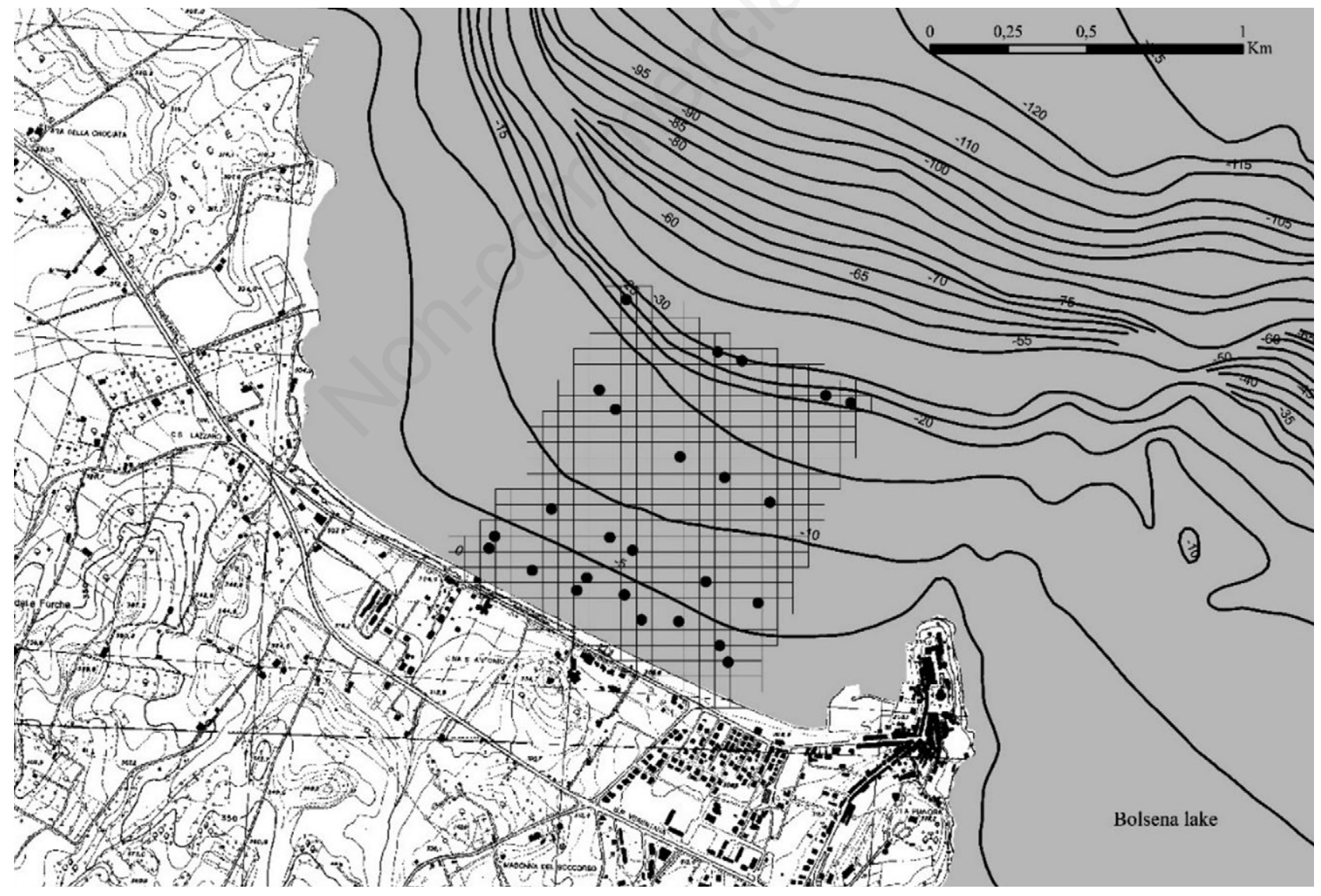

Fig. 2. Example map of the spatial arrangement of the sampling plots (black points) along an experimental homogenous littoral sector, in the present case the map refers to the Bolsena Lake. 
munities or the bare sediment $( \pm 0.5 \mathrm{~m})$ using a multiple probe (Hanna Instruments, HI 9828). At the same time, water samples were collected using a Ruttner bottle (1 L) and immediately processed and kept in cold storage at around $4^{\circ} \mathrm{C}$ for subsequent analysis: $100 \mathrm{ml}$ were filtered with GF/C glass-fiber filters (Whatman, Maidstone, UK) for $\mathrm{NH}_{4}^{+}, \mathrm{NO}_{3}^{-}$, soluble reactive phosphorous (SRP) determinations and $40 \mathrm{ml}$ of unfiltered water were collected for TP and TN determination. All analyses were performed using standard spectrophotometric methods (APHA, 1998). Three sediment cores were simultaneously collected using Plexiglass core tubes $(20 \times 4$ i.d. $\mathrm{cm})$. After collection, the cores were kept on ice and returned to the laboratory within six hours. Upon reaching the laboratory, the first five $\mathrm{cm}$ of each core were extruded and each sediment slice was immediately homogenized and samples collected using cutoff $10 \mathrm{~mL}$ syringes for the determination of organic matter (OM) and total phosphorus (TPsed) content. OM was determined as dry weight loss after ignition at $450^{\circ} \mathrm{C}$ for $2 \mathrm{~h}$ of $0.5 \mathrm{~g}$ of dry sediment, while TPsed was determined on ignited sediment according to the acid extraction method (Aspila et al., 1976).

A fluorimeter cyclops-7 equipped with probes for the characterization of the Phycocyanin, Chlorophyll a and Phycoerythrin pigments was used to detect their relative algal fluorimetric units as well as to estimate the colored dissolved organic matter (CDOM). At the same time, the amount of light radiation (LR) that reaches the canopy was measured using a Li-cor detector (PAR LI-192SA Underwater Quantum Sensor). Starting from the Li-cor data, we derived the vertical diffuse attenuation coefficient $\left(K_{d}\right)$ according to Kirk's equation (1994), based on the photosynthetically active radiation (PAR) at a given depth ( $\mathrm{z}$ ) and at the water surface (water-atmosphere interface).

\section{Checkerboard score and null model analysis}

To test the non-random co-occurrence of macrophytes, a null model analysis was performed. The analysis was applied to the species $\mathrm{x}$ depth zones matrix, using the SIM9 algorithm (Gotelli, 2000) according to Boschilia et al. (2008). The randomized matrix generates casual distribution (the so-called null models). The software used (EcoSim 700; Gotelli and Entsminger, 2002) calculated an index to evaluate the species segregation in the observed and expected matrices. If communities have a not randomly co-occurrence pattern, the index of the observed matrix will be significantly different from the mean of the randomized matrices. In this context, we used the checkerboard score (C-score) index to reveal the existence of competitionbased differences among communities (Stone and Roberts, 1990), supporting the outputs of the Canonical Correspondence Analysis (CCA) method that is devoted to understand distributions based on abiotic variables. To evaluate the presence of a non-random pattern, driven by the environ- mental factors reported in previous studies, we used the total matrix of 125 plots (10,000 randomizations). To evaluate the randomness of the distribution in each lake, we tested the null models on the matrices of single lakes (25 plots, 10,000 randomizations).

\section{CCA and null model analysis}

A CCA was performed using species and environmental data matrices to analyze the influence of environmental variables on specie distribution and to explain the variability detected within and between lakes. All the analyses were conducted using the vegan package in the R-software ( $\mathrm{R}$ core team, 2017). Data were normalized by applying a logarithmic transformation to the dataset. A Pearson's correlation analysis was first conducted to determine the univariate relations between all the study environmental variables to avoid the use of dependent (i.e., covariates) factors in the CCA. We set the threshold at $\mathrm{R}=0.6$ in order to detect any correlation between two significant environmental variables avoiding collinearity (Guareschi et al., 2015). As a result, the following variables were selected for the subsequent analysis: water TP, $\mathrm{TN}, \mathrm{NO}_{3}^{-}$, T, Cond, LR (expressed as $\mu \mathrm{E} \mathrm{m}^{-2}$ ), CDOM, Chla, sediment OM and TPsed.

Unlike many other authors who used depth as an ecological parameter, we excluded the use of depth data from the analysis in advance for two reasons. First, because both T and LR, as well as other variables, were closely correlated with the depth gradient; second, since we used depth as a key factor in selecting sample plots, the use of this variable may have altered the statistical analysis outputs or masked the relative importance of the other environmental determinants. By excluding the depth data, we wished to avoid any tautological entailment. Nevertheless, by means of the function "ordisurf" of the "vegan" package in $\mathrm{R}$, we fitted the depth into ordination diagram. Ordisurf draws the surface of an environmental determinant into ordination diagram using a GAM model.

To evaluate the influence of randomness on the proportion of total variance explained by the environmental variables, the original dataset was split into two different lake groups according to the $\mathrm{C}$-score performance: lakes with a non-random (group A) and those with a random macrophyte distribution (group B). A CCA was then performed by considering each of the two groups separately to determine whether the total variance explained by the environmental variables of the non-random group A is significantly higher than the total variance explained in the first CCA performed by considering all 125 sample plots. When the number of samples in a matrix is reduced, the total variance decreases whereas the total variance explained increases. To avoid this problem and to determine whether the increase was significant as opposed to being related to the lower number of sampling plots considered 
in the analysis, the results obtained were compared with those obtained by using simulated macrophyte distributions (10,000 randomizations) created with a random extraction of plots from the original matrix. It is thus possible to consider the effect due to the change in the sample size and the true improvement in the variance explained. All the sample plots were inserted in the matrix, even if devoid of macrophytes. Consequently, a dummy column with cover values of 1 was inserted to perform the aforementioned analyses.

\section{RESULTS}

\section{Physical and chemical variables}

In the water layer between 1.5 and $6 \mathrm{~m}, \mathrm{~T}, \mathrm{pH}$ and $\mathrm{DO}$ were relatively constant and above $23.5^{\circ} \mathrm{C}, \mathrm{pH} 8.00$ and $100 \%$ of saturation, respectively. These parameters dropped in the 1.5-20 $\mathrm{m}$ range according to the lake size: the smaller the lake, the greater the reduction. A minimum of $8.7^{\circ} \mathrm{C}$ associated with low DO (39\%) was recorded at a depth of $20.0 \mathrm{~m}$ in Lake Vico, whereas a minimum of pH 6.45 was recorded at a depth of $20 \mathrm{~m}$ in Lake Martignano. Both lakes Bracciano and Bolsena yielded T values always above $11^{\circ} \mathrm{C}, \mathrm{pH} 7.39$ and $100 \%$ of DO saturation. Cond varied somewhat, ranging between $268 \mu \mathrm{S} \mathrm{cm}^{-1}$ (at Lake Nemi at a depth of $12.0 \mathrm{~m}$ ) and $541 \mu \mathrm{S} \mathrm{cm}^{-1}$ (at Lake Bolsena at a depth of $1.5 \mathrm{~m}$ ) (Supplementary Tab. 1). Similarly, $\mathrm{NO}_{3}{ }^{-}$and $\mathrm{TN}$ varied considerably with values of 20.0-167.2 $\mu \mathrm{g} \mathrm{L}^{-1}$ and 50.0-514.89 $\mu \mathrm{g} \mathrm{L}^{-1}$, respectively. By contrast, SRP and TP values varied less, with values of 1.2-16.24 $\mu \mathrm{g} \mathrm{L}^{-1}$ and 5-38.9 $\mu \mathrm{g} \mathrm{L}^{-1}$, respectively (Supplementary Tab. 1).

Relative algal and CDOM fluorimetric units exhibited similar patterns. The highest values were recorded at the greatest depths (between 12.0 and 20.0 meters). Phycocyanin, Chla and Phycoerythrin pigments peaked in Lake Vico at a depth of $20.0 \mathrm{~m}$, with Relative fluorimetric unit $(\mathrm{RFU})$ mean values ( \pm standard deviation $=\mathrm{SD}$ ) of $582 \pm 199$, $720 \pm 163$ and $238 \pm 62$, respectively. CDOM yielded its maximum value, equal to $267 \pm 4$ (SD) RFU, in Lake Nemi at a depth of $20.0 \mathrm{~m}$ (Supplementary Tab. 1). For $K d$, the collected values reflected comparable conditions. The highest values were recorded in Lakes Vico and Nemi, above all in the first meters of depth, thus indicating a rapid extinction of underwater radiation. In Lake Nemi, $K_{d}$ ranged between $-0.53 \pm 0.06$ (mean $\pm \mathrm{SE}$ ) and $-0.51 \pm 0.17$, at a depth of 1.5 and $3.0 \mathrm{~m}$, respectively (Supplementary Fig. 1).

Sediment OM content ranged between 0.2 and $36.2 \%$, with the highest values being recorded in lakes Vico $(25.2 \%$ at $1.5 \mathrm{~m}$ of depth) and Nemi (36.2\% at $1.5 \mathrm{~m}$ of depth). TPsed displayed a similar pattern, with a minimum of 0.2 (recorded in Lake Bolsena) and a maximum of 3.1 mg P g${ }^{-1}$ (recorded at Lake Nemi) (Supplementary Tab. 1).

\section{Macrophyte characterization}

A total of 24 macrophytes were recorded: 10 Characeae, one bryophyte (Fontinalis squamosa Hedw.) and 13 vascular plants. M. spicatum was detected in all the lakes, whereas six species were recorded for a single littoral sector [Baldellia ranunculoides (L.) Parl., F. squamosa and Potamogeton lucens L. at Lake Bolsena, Nelumbo nucifera Gaertn., and Potamogeton nodosus Poir. at Lake Nemi, Potamogeton x nitens Weber at Lake Bracciano] (Supplementary Tab. 1). As expected, the highest macrophyte diversity $(2.9 \pm 1.9$ species per plot, $\mathrm{SD}$ ) was detected closest to the surface (from 1.5 to 3.0 $\mathrm{m}$ ), while very poor or monospecific communities were

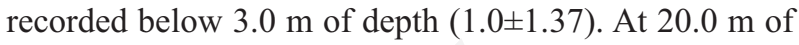
depth, macrophytes were recorded exclusively at Lake Bracciano [dominated by Nitella opaca (C. Agardh ex Bruzelius) C. Agardh 1824]. Aquatic vegetation at Lake Nemi instead ceased at a depth of six meters (dominated by Ceratophyllum demersum L.). The richest plot, consisting of nine species, was recorded in Lake Bolsena at a depth of $3.0 \mathrm{~m}$.

\section{Macrophyte depth distribution and co-occurrence}

In lakes Bracciano, Vico and Martignano there was a clear zonation in aquatic vegetation depending on the depth. As expected, a typical community was identified in each belt investigated. At a depth of between 1.5 and $3.0 \mathrm{~m}$, vascular species emerged as the dominant and constant taxa coupled with a limited number of stoneworts, such as Chara aspera Detharding ex Wildenow 1809, C. vulgaris Linneaus 1753 and C. hispida L. sensu auct. nonnull. By contrast, below a depth of $6.0 \mathrm{~m}$, stoneworts represented the dominant and constant species, particularly C. globularis, whereas the vascular species became rare and localized. Conversely, at Lake Nemi no clear differentiation between the investigated communities along the depth gradient was observed despite the presence of a clear gradient in the TP, $\mathrm{NO}_{3}{ }^{-}$and $\mathrm{TN}$ concentrations in the sediment and water, respectively. Lake Bolsena yielded a simplified model in which there was a clear distinction between shallow and deep communities (Supplementary Tab. 1).

The CCA revealed the presence of two main gradients (Fig. 3, above panel). A not trophic gradient within lakes, correlated with LR and T values (which decreased along the depth gradient, Fig. 3, below panel) and Chl- $a$ concentrations (which increased along the depth gradient), and a second gradient between lakes, correlated with TPs and $\mathrm{OM}$ availability. In general, the increased availability of nutrients (such as water TN, sediment OM and TPsed) promoted the dominance of vascular species at shallow depths (M. spicatum, P. nodosus and Najas minor); while at deep depths are favored stoneworts (C. globularis and 
Nitellopsis obtusa) in conjunction of low T and LR values. By contrast, $B$. ranunculoides, $P$. lucens, and $P$. perfoliatus were dominant in plots with low concentrations of water TN, Chl- $a$, CDOM and sediment OM and TPsed.

The segregation indices calculated for the sampling plots were significantly greater than the average of the indexes based on null models $(\mathrm{P}<0.05)$ obtained from the overall dataset of 125 plots (Fig. 4). Thus, the pattern of species distribution across lakes was not random. This re- sult supports the idea that species associations within communities are not random and that species are not-randomly co-occurring but they are strictly regulated by the environmental gradient of lakes.

At the lake scale, the C-score was significantly higher than expected only in three out of five cases in analysis. The macrophytes co-occurrence pattern was random at lakes Bolsena and Nemi, which indicates that there was no clear spatial co-occurrence pattern of the species in
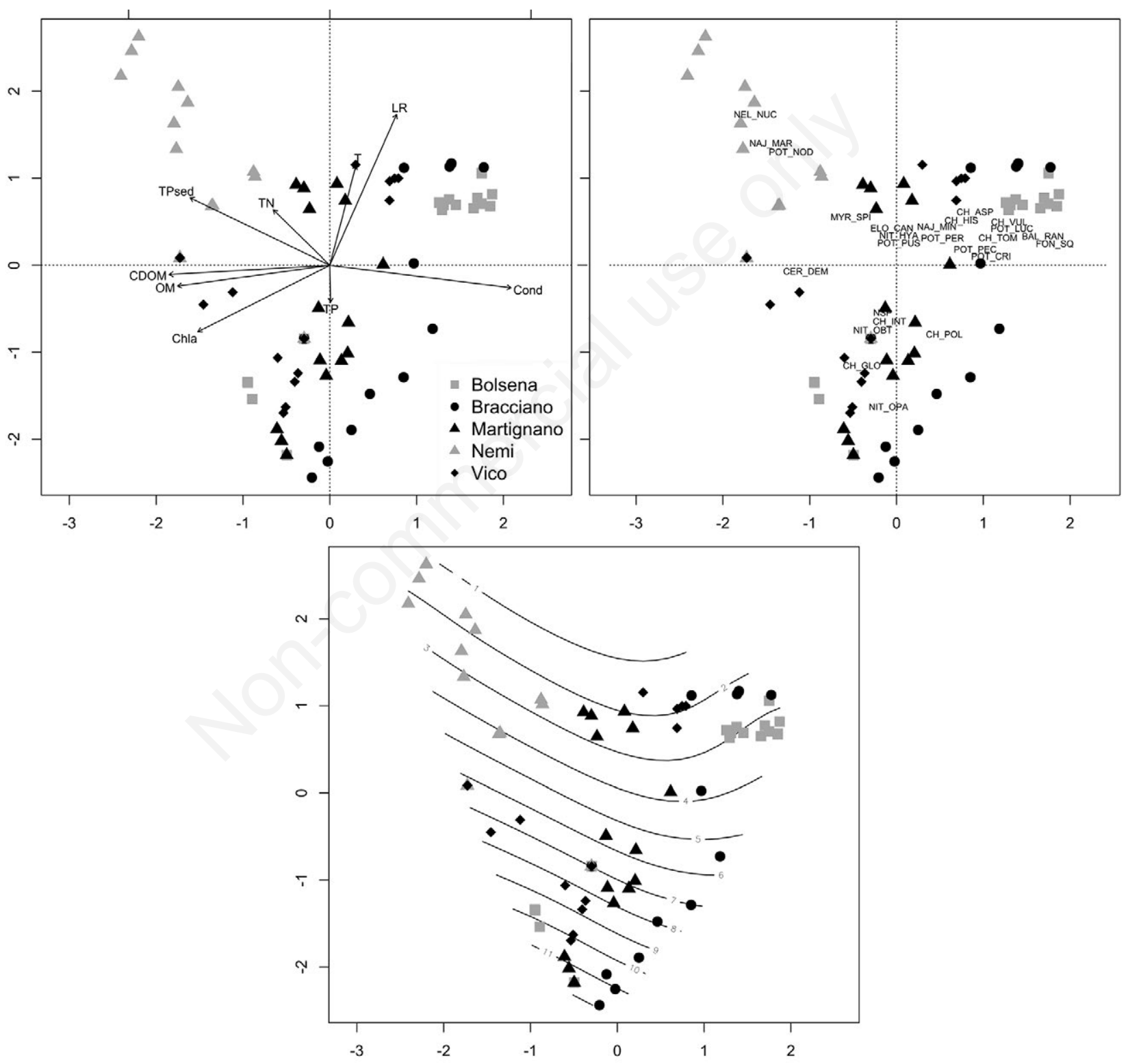

Fig. 3. CCA ordination plots of the ecological gradients obtained by the backward selection for the aquatic vegetation of lakes investigated (above panels). On the left the sampled plots and the environmental drivers, on the right the sampled plots and the species. In the below panel, on the same CCA ordination plot, a projection of depth of the plots onto ordination as a non-linear surface. The total inertia explained is $32 \%$. OM, sediment organic matter; CDOM, colored dissolved organic matter in the water; TPs, total phosphorus in the sediment; TN, total nitrogen in the water; $\mathrm{T}$, water temperature; LR, light radiation measured as $\mu \mathrm{E} \mathrm{m}^{-2}$; Cond, conductivity of the water; TP, total phosphorus of the water; Chla, cholorophyll $a$ in the water; for species abbreviation see Supplementary Tab. 1. 
these lakes. When the lakes in which the $\mathrm{C}$-score analysis revealed a random co-occurrence pattern of species were excluded from the CCA (group B: Bolsena and Nemi, 50 plots), the variance explained by the environmental parameters increased from $36 \%$ to $44 \%$. This increase is significantly correlated with the exclusion of lakes in which a random co-occurrence pattern was detected. This finding is confirmed by the second null model analysis (Supplementary Fig. 2) because the variance explained by the CCA on the plots belonging to lakes Bracciano, Vico and Martignano is significantly higher $(\mathrm{P}<0.01)$ than the vari- ance of null models based on 75 plots randomly extracted from the observed matrix.

\section{DISCUSSION}

\section{Macrophyte co-occurrence in deep lakes}

We demonstrate that macrophyte co-occurrence in deep lakes is structured according to a non-random pattern comparable to the checkerboard scheme (Diamond, 1975). This aspect has previously investigated exclusively
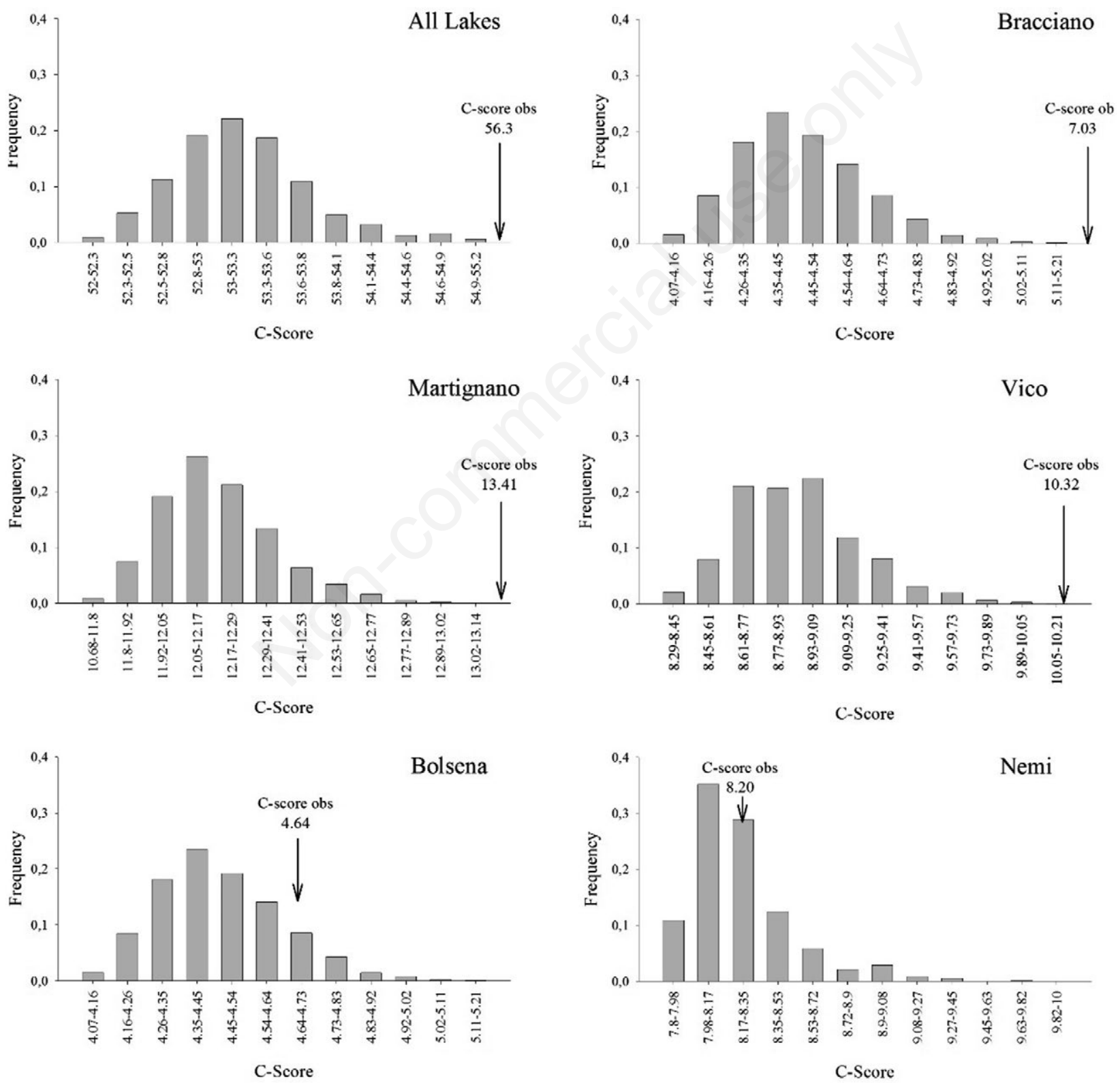

Fig. 4. Histograms of the observed and expected values of the C-score in the whole dataset and at the single lake scale; the arrows correspond to the values obtained for the recorded macrophyte distributions. 
in temperate marshes (Shipley and Keddy, 1987), in lacustrine shoreline vegetation (Keddy, 1983), in a heterogeneous set of shallow lakes (Chmara et al., 2013), and in tropical floodplain lagoons (Boschilia et al., 2008). Indeed, the null model analysis we performed showed that deep lake macrophytes interact, as a whole, in a non-random fashion and some explanatory ecological factors drive macrophyte patterns (LR, T, within the lakes; Chl$a$, Cond and sediment parameters between the lakes).

However, unbundling the analysis at the lake scale, the macrophyte co-occurrence in lakes Bolsena and Nemi, unlike that in lakes Vico, Bracciano and Martignano, seemed to follow a random distribution. A possible explanation is that the environmental determinants of the nonrandom macrophyte co-occurrence observed for lakes Vico, Bracciano and Martignano are either weaker or are offset by other determinants (i.e., not trophic) in the lakes with a non-significant $\mathrm{C}$-score (lakes Bolsena and Nemi). Indeed, the absence of a clear macrophytes depth gradient in lakes Bolsena and Nemi may be associated with their generally unstable and dynamic water physical and chemical conditions. Lake Nemi changed dramatically at the start of the $20^{\text {th }}$ century (Marchesoni, 1940), went through a hypertrophic crisis in the 1970s (Avena and Scoppola, 1987), and only recently experienced an improvement in water quality and vegetation expansion (Azzella et al., 2014). By contrast, the macrophyte representativeness in Lake Bolsena has decreased dramatically in recent years after a long period of growing floristic richness (Azzella et al., 2014), probably because of local climatic variability (Bolpagni et al., 2016b).

These findings are consistent with those reported by the few authors who have investigated macrophyte co-occurrence models (Boschilia et al., 2008; Logue et al., 2011; Chmara et al., 2013). When Boschilia and colleagues (2008) investigated the C-score at a coarse spatial scale of analysis in several lagoons across the Paraná River floodplain, they found a non-random macrophyte arrangement due to ecological differences. When they analyzed only a portion of the data set, i.e., small lagoons disconnected from the system of the Paraná River, they found a random pattern and suggested that it was due to the emergence of several ecological factors in these situations than in tropical floodplain lagoons. The general instability of these systems, combined with the temporary predominance of competitive interactions between species in search of new euphotic zones to colonize, is likely to underlie these random patterns, thereby contributing to the definition of a new equilibrium. Chmara et al. (2013) recorded similar results in shallow lakes in Poland.

\section{Environmental determinants}

The CCA analysis confirmed the existence of recurrent macrophyte distribution patterns that were strictly de- pendent on the trophic status of lakes. However, a clear gradient in macrophyte community patterns was observed as an effect of significant differences in physical and chemical conditions between lakes.

As expected, Cond, Chl- $a$ and nutrient concentrations, particularly in the surficial sediments, are the main environmental determinants of differences in macrophyte distribution gradients between lakes. Our results are in keeping with the findings of several previous studies (e.g., Chappuis et al., 2014; Schneider et al., 2015). However, the fact that the macrophyte communities appear to be driven by sediment TPsed to a greater extent than by the $\mathrm{TN}$ concentration in water, and above all that the water TP is not significantly related to the macrophyte distribution patterns suggests that sediment parameters play a more important role than water conditions in the spatial arrangement of macrophytes. It is not a complete novelty (see Carignan and Kalff, 1980), but it is generally underestimated (Capers et al., 2010). However, our study lends further support to this evidence and highlights the need for further investigations. Indeed, the majority of both earlier and more recent works on this topic focused predominantly, or even exclusively, on water conditions when analyzing macrophyte patterns, neglecting the potential role of sediment (Kolada, 2010; Alahuhta, 2015; Lukács et al., 2015; Pulido et al., 2015). Furthermore, previous investigations that did analyze the depth distribution of macrophytes often included depth among the environmental determinants tested, thereby limiting the analytical potential of the studies (Azzella et al., 2014 and references therein), or used data mainly from shallow ecosystems (Søndergaard et al., 2013). In this regard, the present dataset based on deep lakes sheds light on a relatively wide range of depths (down to $20.0 \mathrm{~m}$ ) and provides useful information capable to integrate the data available for shallow lakes. For instance, the present results could allow solving part of the uncertainty highlighted by Capers et al. (2010) considering the importance of local and regional processes in driving macrophyte communities. Specifically, the recorded stochasticity rather than depend on the processes of species' colonization and persistence, may result from the underestimation of the sediment's role as well as the influence of the trophic dynamics of the studied lakes.

\section{Implications for ecological study, biomonitoring and lake classification}

The majority of recent works on the relationship between macrophytes and the environment, which have generally been performed on very large datasets and have thus been characterized by a very marked variance, did not detect any degree of randomness in macrophyte cooccurrence before the role of expected driving factors was tested (Kolada, 2010; Alahuhta, 2015). Our findings in- 
dicate that not testing these factors may result in a misinterpretation of the determinants of macrophyte co-occurrence patterns as well as of their edaphic determinants. Indeed, we may assume that experimental results in numerous previous studies were over-interpreted, generating distorted evaluations of the role of environmental factors in driving macrophyte distribution as well as of the reliability of macrophytes as markers of the ecological status of colonized environments. Indeed, there has been a growing consensus on the existence of weak relationships between changes in "macrophyte dominance" and major environmental variables, usually regarded as the main determinants of aquatic vegetation dynamics (Demars et al., 2012). These authors confirmed the predominance of nonhuman pressures in driving the variability in river macrophyte indices, suggesting that not-trophic determinants (e.g., temperature, lake area) play an important role in this variability. Furthermore, recent evidence suggests that macrophyte communities that exhibit marked inter-annual fluctuations and stochastic interactions with external disturbance events or weather extremes are characterized by intrinsic high dynamicity (Wiegleb et al., 2014). With respect to these considerations, our approach can complement other types of surveys, especially those aimed at investigating the long-term changes in macrophyte communities using sedimentary macrofossils as verified by Levi et al. (2014) in several Mediterranean lakes.

Although the first long-term data were collected for river systems, it is reasonable to presume that lacustrine macrophyte communities are also characterized by alternating phases of establishment and development, as demonstrated by Bolpagni et al. (2016b) in the short term (a three-year field survey), that do not appear to be controlled by physical and chemical environmental determinants. For example, in summer Lake Bracciano is frequently affected by intense phenomena of "detachment and emergence" of large portions of the submerged beds of stoneworts, which probably favor the periodical replacement of "aged communities" by new formations. In the early stages of colonization, these new "open patches" are frequently colonized by annual species (such as Najas marina L.) before being re-colonized by stoneworts. Synthetic or global assessments generally consider extremely large datasets that cover very long periods of time, which requires the simultaneous analysis of data collected in time intervals spanning more than 10-20 years. The potential distortive effects induced by the underestimation of the role of macrophyte inter-annual fluctuations are generally not considered in this case either.

\section{CONCLUSIONS}

Summarizing, a non-random model describes the depth co-occurrence of macrophytes in deep lakes under stable trophic conditions and under low human impact. Moreover, given the presence of a clear partitioning of macrophytes, which is demonstrated by the coexistence of vascular-dominated stands at depths closest to the surface (1.5 to 6.0 meters) and stonewort-dominated beds at depths of more than six meters, we believe that significant $\mathrm{C}$-scores are closely related to a trophic stable state of a deep lake. Exclusively low nutrient loads, in both water and sediments, may result in the characteristic macrophyte zonation along the depth gradient. If C-scores are not adequately implemented in ecological investigations, random macrophyte co-occurrence patterns could be used to define the macrophyte determinants largely invalidating their significance.

In comparison with the results obtained by $\mathrm{Fu}$ et al. (2014), we further put emphasis on the pivotal role of habitat filtering, stressing on the role of sediment conditions, in driving macrophyte community assembly. If it is clear that water depth shaped the macrophyte spatial patterns in close association with nutrients and light, our analyses introduce additional considerations on the importance of the whole-lake trophic status and dynamics in explaining the role and importance of environmental determinants as macrophyte filters. Consequently, any study on the relationship between macrophytes and aquatic environmental conditions, as well studies based on the use of macrophytes in monitoring, must include an assessment of the community structure according to one of the community pattern theories. A failure to do so would lead to an over-estimation of the macrophyte bioindication value, which would in turn seriously compromise any attempt to accurately assess the conservation status of lakes.

\section{ACKNOWLEDGMENTS}

This work was supported by University of Parma and Sapienza University of Rome, and it is part of the results of the MIVOLS project (Macrophytes of the Italian VOlcanic Lake System). Dr. Francesco Maria Sabatini for the useful (and fundamental) help in the implementation of the null model used to evaluate the influence of randomness on the proportion of total variance explained by the environmental variables in the CCA. Dr. L. Baker provided linguistic assistance.

\section{REFERENCES}

Alahuhta J, 2015. Geographic patterns of lake macrophyte communities and species richness at regional scale. J. Veg. Sci. 26:564-575.

APHA, 1998. Standard Methods for the Examination of Water and Waste Water. American Public Health Association, Washington DC: $874 \mathrm{pp}$.

Aspila KI, Agemian H, Chau ASY, 1976. A semi-automated 
method for the determination of inorganic, organic and total phosphate in sediments. Analyst 101:187-197.

Avena GC, Scoppola A, 1987. Features of the hydrophytes and helophytes communities, p. 75-94. In: V. Carunchio (ed.), Evaluation of the environmental situation of Lake Nemi. Università degli Studi di Roma "La Sapienza" and Provincia di Roma.

Azzella MM, 2014. Italian Volcanic lakes: a diversity hotspot and refuge for European charophytes. J. Limnol. 73:502-510.

Azzella MM, Bolpagni R, Oggioni A, 2014. A preliminary evaluation of lake morphometric traits influence on the maximum growing depth of macrophytes. J. Limnol. 73:400-406.

Azzella MM, Ricotta C, Blasi C, 2013. Aquatic macrophyte diversity assessment: Validation of a new sampling method for circular-shaped lakes. Limnologica 43:492-499.

Azzella MM, Rosati L, Iberite M, Bolpagni R, Blasi C, 2014. Changes in aquatic plants in the Italian volcanic-lake system detected using current data and historical records. Aquat. Bot. 112:41-47.

Bolpagni R, Racchetti E, Laini A, 2016a. Fragmentation and groundwater supply as major drivers of algal and plant diversity and relative cover dynamics along a highly modified lowland river. Sci. Total Environ. 568:875-884.

Bolpagni R, Laini A, Azzella MM, 2016b. Short time dynamics of submerged aquatic vegetation diversity and abundance in deep lakes. Appl. Veg. Sci. 19:711-723.

Bornette G, Puijalon S, 2011. Response of aquatic plants to abiotic factors: a review. Aquat. Sci. 73:1-14.

Boschilia SM, Oliveira EF, Thomaz SM, 2008. Do aquatic macrophytes co-occur randomly? An analysis of null models in a tropical floodplain. Oecologia 156:203-214.

Carignan R, Kalff J, 1980. Phosphorus sources for aquatic weeds: water or sediments? Science 207:987-989.

Capers RS, Selsky R, Bugbee GJ, 2010. The relative importance of local conditions and regional processes in structuring aquatic plant communities. Freshwater Biol. 55:952-966.

Carvalho L, Solimini AG, Phillips G, Pietilainen O-P, Moe J, Cardoso AC, Solheim AL, Ott I, Søndergaard M, Tartari G, Rekolainen S, 2009. Site-specific chlorophyll reference conditions for lakes in Northern and Western Europe. Hydrobiologia 633:59-66.

Chappuis E, Gacia E, Ballesteros E, 2014. Environmental factors explaining the distribution and diversity of vascular aquatic macrophytes in a highly heterogeneous Mediterranean region. Aquat. Bot. 113:72-82.

Chmara R, Szmeja J, Ulrich W, 2013. Patterns of abundance and co-occurrence in aquatic plant communities. Ecol. Res. 28:387-395.

Demars BO, Potts JM, Tremolieres M, Thiebaut G, Gougelin N, Nordmann V, 2012. River macrophyte indices: Not the Holy Grail! Freshwater Biol. 57:1745-1759.

Diamond JM, 1975. Assembly of species communities, p. 342444. In: M.L. Cody and J.M. Diamond (eds.), Ecology and evolution of communities. Harvard University Press.

Duberstein JA, Conner WH, Krauss KW, 2014. Woody vegetation communities of tidal freshwater swamps in South Carolina, Georgia and Florida (US) with comparisons to similar systems in the US and South America. J. Veg. Sci. 25:848-862.

Fu H, Zhong J, Yuan G, Xie P, Guo L, Zhang X, Xu J, Li Z, Li W, Zhang M, Cao T, Ni L, 2014. Trait-based community as- sembly of aquatic macrophytes along a water depth gradient in a freshwater lake. Freshwater Biol. 59:2462-2471.

Genkai-Kato M, Carpenter SR, 2005. Eutrophication due to phosphorus recycling in relation to lake morphometry, temperature, and macrophytes. Ecology 86:210-219.

Gotelli NJ, 2000. Null model analysis of species co-occurrence patterns. Ecology 81:2606-2621.

Gotelli NJ, Entsminger GL, 2002. EcoSim: null models software for ecology. Ver. 7.0. Acquired Intelligence and Kesey-Bear, Jericho.

Guareschi S, Abellán P, Laini A, Green AJ, Sánchez-Zapata JA, Velasco J, Millán A, 2015. Cross-taxon congruence in wetlands: Assessing the value of waterbirds as surrogates of macroinvertebrate biodiversity in Mediterranean Ramsar sites. Ecol. Indic. 49:204-215.

Jensén S, 1979. Classification of lakes in southern Sweden on the basis of their macrophyte composition by means of multivariate methods. Plant Ecol. 39:129-146.

Keddy PA, 1983. Shoreline vegetation in Axe Lake, Ontario: effects of exposure on zonation patterns. Ecology 64:331-344.

Kirk JTO, 1994. Light and photosynthesis in aquatic ecosystems. University Press, Cambridge: 401 pp.

Kolada A, 2010. The use of aquatic vegetation in lake assessment: testing the sensitivity of macrophyte metrics to anthropogenic pressures and water quality. Hydrobiologia 656:133-147.

Lacoul P, Freedman B, 2006. Environmental influences on aquatic plants in freshwater ecosystems. Environ. Rev. 14:89-136.

Levi EE, Çakiroğlu AY, Bukal T, Odgaard BV, Davidson TA, Jeppensen E, Beklioğlu M, 2014. Similarity between contemporary vegetation and plant remains in the surface sediment in Mediterranean lakes. Freshwater Biol. 59:724-736.

Logue JB, Mouquet N, Peter H, Hillebrand H, Group MW, 2011. Empirical approaches to metacommunities: a review and comparison with theory. TREE 26:482-491.

Lukács BA, Tóthmérész B, Borics G, Várbíró G, Juhász P, Kiss B, Müller Z, G-Tóth L., Erős T, 2015. Macrophyte diversity of lakes in the Pannon Ecoregion (Hungary). Limnologica 53:74-83.

Marchesoni V, 1940. [Il Fitoplancton del Lago di Nemi prima e dopo l'abbassamento del suo livello (1923-1939)].[Article in Italian]. Int. Rev. ges. Hydrobiol. Hydrogr. 40:305-345.

Melzer A, 1999. Aquatic macrophytes as tools for lake management. Hydrobiologia 395:181-190.

Penning WE, Dudley B, Mjelde M, Hellsten S, Hanganu J, Kolada A, van den Berg M, Poikane S, Phillips G, Willby N, 2008a. Using aquatic macrophyte community indices to define the ecological status of European lakes. Aquat. Ecol. 42:253-264.

Penning WE, Mjelde M, Dudley B, Hellsten S, Hanganu J, Kolada A, van den Berg M, Poikane S, Phillips G, Willby N, 2008b. Classifying aquatic macrophytes as indicators of eutrophication in European lakes. Aquat. Ecol. 42:237-251.

Presley JP, Higgins CL, Willing MR, 2010. A comprehensive framework for the evaluation of metacommunity structure. Oikos 119:908-917.

Pulido C, Riera JL, Ballesteros E, Chappuis E, Gacia E, 2015. Predicting aquatic macrophyte occurrence in soft-water oligotrophic lakes (Pyrenees mountain range). J. Limnol. 74:143-154.

R Core Team, 2017. R: A language and environment for statis- 
tical computing. R Foundation of Statistical Computing. Vienna, Austria.

Schneider B, Cunha ER, Marchese M, Thomaz SM, 2015. Explanatory variables associated with diversity and composition of aquatic macrophytes in a large subtropical river floodplain. Aquat. Bot. 121:67-75.

Scheffer M, Hosper SH, Meijer ML, Moss B, 1993. Alternative equilibria in shallow lakes. Trends Ecol. E 8:275-279.

Shipley Bvol., Keddy PA, 1987. The individualistic and community-unit concepts as falsifiable hypotheses. Plant Ecol. 69:47-55.

Søndergaard M, Phillips G, Hellsten S, Kolada A, Ecke F, Mäemets H, Mjelde M, Azzella MM, Oggioni A, 2013. Maximum growing depth of submerged macrophytes in European lakes. Hydrobiologia 704:165-177.
Stone L, Roberts A, 1990. The checkerboard score and species distributions. Oecologia 85:74-79.

Ulrich W, Gotelli NJ, 2013. Pattern detection in null model analysis. Oikos 122:2-18.

Vestergaard O, Send-Jensen K, 2000. Alkalinity and trophic state regulate aquatic plant distribution in Danish lakes. Aquat. Bot. 67:85-107.

Wiegleb G, Bröring U, Filetti M, Brux H, Herr W, 2014. Longterm dynamics of macrophyte dominance and growth-form types in two north-west German lowland streams. Freshwater Biol. 59:1012-1025.

Wilson SD, Keddy PA, 1986. Measuring diffuse competition along an environmental gradient: results from a shoreline plant community. Am. Nat. 127:862-869. 